\title{
Thoracic epidural for modified radical mastectomy in an asthmatic patient
}

\section{Aarif A. A. R. Rangrez, Chetan Gopal Agrawal*, Dattatraya Gangurde}

Department of Anaesthesia, Government Medical College and Hospital, Aurangabad, Maharashtra, India

Received: 05 February 2020

Accepted: 21 February 2020

\section{*Correspondence:}

Dr. Chetan Gopal Agrawal,

Email: drchetanagrawal87@gmail.com

Copyright: () the author(s), publisher and licensee Medip Academy. This is an open-access article distributed under the terms of the Creative Commons Attribution Non-Commercial License, which permits unrestricted non-commercial use, distribution, and reproduction in any medium, provided the original work is properly cited.

\begin{abstract}
Thoracic epidural anaesthesia is one of the safe and good alternative to general anaesthesia in high risk patients of chronic obstructive pulmonary disease and asthma where general anaesthesia is contraindicated. A 55 years old female patient was scheduled for modified radical mastectomy on account of advanced carcinoma of right breast. The patient was known case of bronchial asthma since 5 years with frequent attacks per week for which she was taking nebulisation with salbutamol and budesonide two times per day. In the pre-operative evaluation, her vitals were within normal limit but on auscultation air entry was reduced all over the chest with bilateral crepts and rhochi present. We did this patient in plaine thoracic epidural anaesthesia without haemodynamic instability. Thoracic epidural anaesthesia and analgesia for mastectomy is feasible, and it offers additional benefits in high-risk patients.
\end{abstract}

Keywords: Thoracic epidural, Modified radical mastectomy, Asthma

\section{INTRODUCTION}

Breast cancer is one of the most commonly seen cancers among females in our country. In India, it accounts for $25 \%$ to $32 \%$ of all female cancers. ${ }^{1}$ It requires various surgical interventions ranging from lumpectomy to mastectomy, along with axillary lymph node clearance. Conventionally general anaesthesia (GA) is the most frequently used technique, but it is associated with inadequate pain control due to lack of residual analgesia and also with other complications such as nausea, vomiting and depression of the immune system. ${ }^{1}$

Various regional anaesthesia techniques have been described for breast surgeries. These include wound infiltration, thoracic epidural anaesthesia, thoracic paravertebral block, and ultrasound-guided interfascial plane blocks such as pectoral nerve (PACS) block type 1 and 2. Beneficial effects of regional anaesthesia include effective anaesthesia and analgesia in the perioperative period, decreased need for opioids, decreased postoperative nausea and vomiting, fewer postoperative pulmonary complications, decreased duration of stay in hospital and reduction in cancer progression. ${ }^{1}$

Thoracic epidural anaesthesia is one of the safe and good alternative to general anaesthesia in high risk patients of COPD and asthma where general anaesthesia is contraindicated. $^{2}$

\section{CASE REPORT}

A 55 years old female patient was scheduled for modified radical mastectomy on account of advanced carcinoma of right breast. The patient was known case of bronchial asthma since 5 years with frequent attacks per week for which she was taking nebulisation with salbutamol and budesonide two times per day.

In the pre-operative evaluation her vitals were within normal limit, airway examination was normal but on auscultation air entry was reduced all over the chest with 
bilateral crepts and rhochi present. Her bedside pulmonary function test was (breath holding time 10 seconds, single breath count 6 seconds). So, we optimised patient with nebulisation, deep breathing exercises, Injectable steroids and antibiotics cover for 5 days. After 5 days there was mild improvement in respiratory system, her X-ray chest was suggestive of COPD changes, noncontrast head computed tomography chest shows hyper-inflated lung field suggestive of bilateral COPD changes, electrocardiography (ECG) was normal, other routine investigations was within normal limits. On the evening before surgery her BP was $140 / 90$ and pulse rate was $88 /$ minute, RR was $20 /$ minute. Based on the comorbid conditions, she was assigned class to III of the American Society of Anesthesiologists classification scheme. She was counselled for thoracic epidural anaesthesia, as general anaesthesia was considered a riskier alternative, and consent for the procedure was obtained.

In operation theatre, a multiparameter monitor was attached to patient, measuring Spo2, non invasive blood pressure, ECG. Baseline values were as follows: PR was 84/min, BP was 140/90 mm $\mathrm{Hg}$, and Spo $2-96 \%$. In the sitting position, a midline thoracic epidural was inserted in T4-T5 space using 18G Tuohys epidural needle and loss of resistance to air technique. The skin epidural depth was $5 \mathrm{~cm}$, and $4 \mathrm{~cm}$ of the epidural catheter was left in situ in the epidural space in cephalad direction, and the catheter was fixed to back.

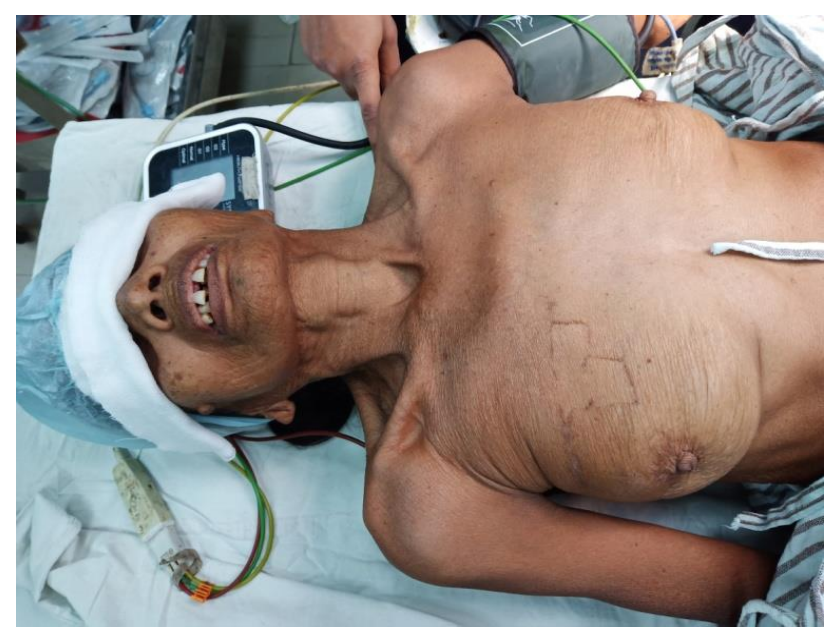

Figure 1: Right carcinoma breast (pre-op).

After a test dose of $3 \mathrm{ml}$ of $1.5 \%$ lidocaine with adrenaline, a loading dose of $5 \mathrm{ml}$ of $2 \%$ lidocaine with adrenaline $1: 200,000$ and $9 \mathrm{ml}$ of ropivacaine $(0.75 \%)$ was given as loading dose.

Ten minutes later, a sensory block height of T1 to T8 was achieved bilaterally, and the surgery commenced. The breast tissues and tumour were excised en bloc, including fibrofatty tissues of the medial aspect of the right axilla. Oxygen was given via face mask at 41 /minute throughout the duration of the surgery, which lasted for 2 hours, 40 minutes. Inj. Ondansetron $4 \mathrm{mg}$ IV, Inj. Midazolam - 1 $\mathrm{mg}$ and Inj. Fentanyl $50 \mathrm{mcg}$ was given.

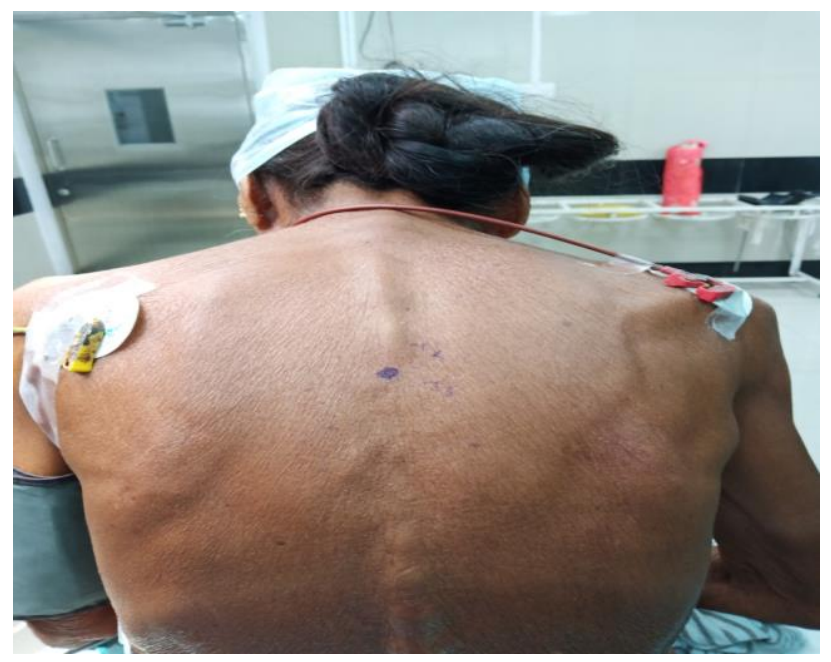

Figure 2: Thoracic level T4-T5.

The estimated blood loss was $600 \mathrm{ml}$; and a total of 1.51 of ringer lactate was infused. The patient remained haemodynamically stable and comfortable throughout the procedure.

Postoperatively, the patient was admitted to the intensive care unit for observation and pain management, which consisted of continuous infusion of $0.2 \%$ Ropivacaine at 4 $\mathrm{ml} /$ hour, for 48 hours. The patient resumed oral feeding about 6 hours postoperatively. The patient was discharged from the ICU and the hospital on the second and sixth postoperative days, respectively.

\section{DISCUSSION}

Mastectomy is traditionally performed under general anaesthesia. In a previous study, Balzarena documented the safety and superiority of thoracic epidural over general anaesthesia in 40 patients scheduled for mastectomy. In that study, thoracic epidural was found to be superior to general anaesthesia in terms of haemodynamic stability, reduced nausea and vomiting, lower analgesic consumption, superior postoperative analgesia, and shorter duration of hospitalisation., ${ }^{1,2}$ Similar observations have been reported by other researchers. ${ }^{1,3,4,5}$

The infrequent use of thoracic epidural anaesthesia for oncologic breast surgeries in our environment may be attributed to fear of potential complications of thoracic epidural, which include spinal injury, epidural haemetoma and abscess, as well as postdural puncture headache. However, with experience and due precautions, these complications are extremely rare. ${ }^{1,5,6}$

Moreover, the benefits of thoracic epidural anaesthesia makes it a technique of choice in high risk patients. ${ }^{1,2}$ Previous studies have identified history of 
hypertension as a risk factor for cardiovascular complications during general anaesthesia. ${ }^{7}$ Hypertension has also reported to be more common intraoperatively in patients undergoing surgeries under general anesthesia compared to thoracic epidural. ${ }^{1,2}$ During general anaesthesia, large increases in blood pressure are usually precipitated by laryngoscopy and intubation, surgical stimulation, and extubation. ${ }^{1,2}$ These airway manipulations are usually avoided in thoracic epidural anaesthesia and hence our patient was haemodynamically stable throughout the procedure.

Surgery in diabetic patients is associated with greater perioperative mortality than surgery in nondiabetic subjects. ${ }^{1,8,9}$ This is due in part to higher incidences of coronary heart disease, hypertension, renal insufficiency and hyperglycemia among patients with diabetes. ${ }^{1,9,10}$ The metabolic response to surgery and anaesthesia promotes hyperglycaemia. This is due to the increased secretions of counterregulatory hormones (cathecolamines, cortisol, glucagon and growth hormone) and excessive release of inflammatory cytokines. ${ }^{1,11}$ The magnitude of the counterregulatory response relates to the severity of surgery, as well as the type of anaesthesia. General anaesthesia has been shown to result in higher blood glucose concentrations compared to local and epidural anaesthesia. ${ }^{9}$ On the other hand, spinal epidural abscess is a rare but potentially life-threatening complication of spinal or epidural anaesthesia. This risk is increased in diabetic patients compared to nondiabetics. ${ }^{12,13}$ However, the risk-benefit assessment of our patient favoured epidural anaesthesia.

Regional anaesthesia, especially epidural where feasible, has been reported to be safer in asthmatic patients compared to general anaesthesia. ${ }^{14}$ Apart from avoiding airway manipulations, which may trigger asthmatic attacks, epidural anaesthesia improves wheezing and ameliorates status asthmaticus. ${ }^{15}$ Although our patient had an asthmatic attack 2 days prior to surgery and was treated, she remained stable throughout the procedure.

Etta et al, previously reported on thoracic epidural anaesthesia for laparotomy in an asthmatic patient. ${ }^{14}$ Their patient developed acute asthmatic attack postoperatively in the general ward, and this was attributed to inadequate analgesia since pentazocine and paracetamol were used as per the surgeon's order for acute pain management. Our patient was admitted to the ICU for continuous epidural analgesia using a syringe pump for at least 48 hours postoperatively. This enabled the patient to receive the full benefit of epidural analgesia, since syringe pumps and nurses trained in epidural analgesia management were not available in the general ward.

\section{CONCLUSION}

Thoracic epidural anaesthesia and analgesia for mastectomy is feasible, and it offers additional benefits in high-risk patients.

\section{ACKNOWLEDGEMENTS}

The authors thank nursing and paramedical staff associated with operation theatre and PACU. Special thanks to surgical departments for their co-operation.

\section{Funding: No funding sources \\ Conflict of interest: None declared \\ Ethical approval: Not required}

\section{REFERENCES}

1. Etta OE, Udeme N. Thoracic epidural for modified radical mastectomy in a high-risk patient. Malawi Med J. 2017;29(1):61-2.

2. Balzarena SD. Comparative study between thoracic epidural block and general anaesthessia for oncologic mastectomy. Rev Bras Anestesiol. 2008;58(6):561-8.

3. Lynch EP, Welch KJ, Carabuena JM, Eberlein TJ. Thoracic epidural anaesthesia improves outcome after breast surgery. Ann Surg. 1995;222(5):663-9.

4. Asegaonkar BN, Zine SR, Takalkar UV, Kulkarni U, Asegaonkar SB, kodlikeri P. Thoracic epidural anaesthesia for modified radical mastectomy in carcinoma of breast patient with chronic obstructive pulmonary disease: A case report. Int J Case Reports Images. 2013;4(5):546-50.

5. Etta OE, Umeh K, Akpan SG. Thoracic epidural anaesthesia for major abdominal surgeries: experience in private hospital setting in Uyo, SouthSouth Nigeria. SAJAA. 2016;22(3):86-8.

6. Tanaka K, Watanabe R, Harada T, Dan K. Extensive application of epidural anaesthesia and analgesic in a university hospital: Incidence of complications related to technique. Reg Anesth. 1993;18(1):34-8.

7. Howel SJ, Sear YM, Yeates D, Goldacre M, Sear JW, et al. Risk factors for cardiovascular death after elective surgery under general anaesthesia. $\mathrm{Br} \mathrm{J}$ Anaesth. 1998;80:14-9.

8. Vishwanath RH. Thoracic Epidural anaesthesia for modified radical mastectomy in type 2 Diabetes mellitus patient. J Med Dent Sci. 2014;3(70):150026.

9. Rehman HU, Mohammed K. Perioperative management of diabetic patients. Curr Surg. 2003;60:607-11.

10. Umpierrez GE, Isaacs SD, Bazargan $\mathrm{N}$, et al. Hyperglycemia: an independent marker of in-hospital mortality in patients with undiagnosed diabetes. J Clin Endocrinol Metab. 2002;87:978-82.

11. Mizock BA. Blood glucose management during critical illness. Rev Endocr Metab Disorder. 2003;4:187-94.

12. Tang HJ, Lin HJ, Liu YC, Li CM. Spinal epidural abscess-experience with 46 patientsand evaluation of prognostic factors. J Infect. 2002;45(2):76-81.

13. Reihsaus G, Waldbaur H, Seeling W. Spinal epidural abscess: a meta-analysis of 915 patients. Neurosurg Rev. 2000;23(4):175-204. 
14. Etta OE, Edubio MN. Awake thoracic epidural anaesthesia for laparotomy: A safer alternative to general anaesthesia in asthmatic patients. Ibom Medical journal. 2014;7(2):6-10.

15. Shono S, Higa K, Katori K, Nitahara K, Hamada T, Kusumoto G, et al. Tracheal Intubation does not Provoke Bronchospasm in Patients with Bronchial
Asthma under Thoracic Epidural Anesthesia. Med Bull Fakuoka Univ. 2008;35:51-156.

Cite this article as: Rangrez AAAR, Agrawal CG, Gangurde D. Thoracic epidural for modified radical mastectomy in an asthmatic patient. Int J Basic Clin Pharmacol 2020;9:506-9. 